\title{
Metal-Organic Frameworks Based on Pyridyl-Tetrazole Ligands Containing Ester or Carboxylate Pendant Arms
}

\author{
Ursula Sheridan \\ NUI Maynooth \\ John Gallagher \\ $D C U$ \\ Morten Bjerrum \\ University of Copenhagen
}

See next page for additional authors

Follow this and additional works at: https://arrow.tudublin.ie/ittsciart

Part of the Inorganic Chemistry Commons, and the Organic Chemistry Commons

\section{Recommended Citation}

Sheridan, U., Gallagher, J.F., Bjerrum, M.J.,Fleming, A., Kelleher, F., McGinley, J. : Metal-organic frameworks based on pyridyl-tetrazole ligands containing ester or carboxylate pendant arms, Inorganica Chimica Acta (2014), doi: http://dx.doi.org/10.1016/j.ica.2014.05.028

This Article is brought to you for free and open access by

the School of Science and Computing at ARROW@TU

Dublin. It has been accepted for inclusion in Articles by an authorized administrator of ARROW@TU Dublin. For more information, please contact

arrow.admin@tudublin.ie, aisling.coyne@tudublin.ie, gerard.connolly@tudublin.ie.

Funder: Irish Research Council

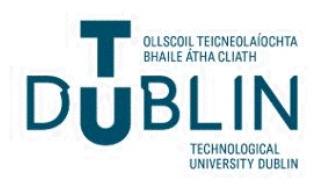




\section{Authors}

Ursula Sheridan, John Gallagher, Morten Bjerrum, Adrienne Fleming, Fintan Kelleher, and John McGinley

This article is available at ARROW@TU Dublin: https://arrow.tudublin.ie/ittsciart/33 


\section{Accepted Manuscript}

Metal-organic frameworks based on pyridyl-tetrazole ligands containing ester or carboxylate pendant arms

Ursula Sheridan, John F. Gallagher, Morten J. Bjerrum, Adrienne Fleming, Fintan Kelleher, John McGinley

PII: S0020-1693(14)00317-X

DOI: http://dx.doi.org/10.1016/j.ica.2014.05.028

Reference: $\quad$ ICA 16010

To appear in: $\quad$ Inorganica Chimica Acta

Received Date: $\quad 28$ March 2014

Revised Date: $\quad 23$ May 2014

Accepted Date: $\quad 24$ May 2014

Please cite this article as: U. Sheridan, J.F. Gallagher, M.J. Bjerrum, A. Fleming, F. Kelleher, J. McGinley, Metalorganic frameworks based on pyridyl-tetrazole ligands containing ester or carboxylate pendant arms, Inorganica Chimica Acta (2014), doi: http://dx.doi.org/10.1016/j.ica.2014.05.028

This is a PDF file of an unedited manuscript that has been accepted for publication. As a service to our customers we are providing this early version of the manuscript. The manuscript will undergo copyediting, typesetting, and review of the resulting proof before it is published in its final form. Please note that during the production process errors may be discovered which could affect the content, and all legal disclaimers that apply to the journal pertain. 


\title{
Metal-organic frameworks based on pyridyl-tetrazole ligands containing ester or carboxylate pendant arms.
}

\author{
Ursula Sheridan, ${ }^{\mathrm{a}}$ John F. Gallagher, ${ }^{\mathrm{b}, *}$ Morten J. Bjerrum, ${ }^{\mathrm{c}}$ Adrienne Fleming, ${ }^{\mathrm{d}}$ Fintan \\ Kelleher, ${ }^{\mathrm{d}}$ and John McGinley.,
}

a Department of Chemistry, National University of Ireland Maynooth, Maynooth, Co. Kildare, Ireland,

${ }^{\mathrm{b}}$ School of Chemical Sciences, Dublin City University, Dublin 9, Ireland,

${ }^{c}$ Department of Chemistry, University of Copenhagen, DK-2100 Copenhagen $\emptyset$, Denmark,

${ }^{\mathrm{d}}$ Molecular Design and Synthesis Group, Department of Science, Institute of Technology Tallaght, Dublin 24, Ireland.

\begin{abstract}
The coordination of pyridyl-tetrazole derivatives containing ester substituents, at either the N1 or N-2 position of the tetrazole ring, with copper(II) chloride results in the formation of either $1: 1$ or 1:2 copper to ligand complexes, depending on the ligand. However, when the ester functionality is changed to a carboxylate group, the resulting complexation reactions yield metal-organic frameworks. The resulting structures vary dramatically in pore size, depending on both reaction solvents and position of carboxylate group on the tetrazole ring. Despite the presence of sodium cations in the reaction mixtures, no sodium incorporation was ever observed in any of the complexes. This report represents the first attempts at producing copper(II) complexes of the N-1 and N-2 carboxylate derivative of this ligand.
\end{abstract}

\section{Keywords}

Tetrazole, pyridine, transition metal, synthesis, X-ray structure, metal-organic framework. 


\section{Introduction}

Metal-organic frameworks (MOFs) have attracted remarkable attention in the past decade as a result of their amazing structural topographies, ${ }^{1}$ as well as their excellent properties and applications, including storage of gases, catalysis, drug delivery, magnetism and luminescence. ${ }^{2}$ A large variety of MOFs have already been synthesised through the selfassembly of ligands and metal ions. However, the prediction of a final outcome in MOF synthesis remains a great challenge. The attainment of MOFs depends on many parameters such as coordination geometries of the metal centres, the coordination sites of the ligand used, metal-ligand ratio, the nature of the counter ions and solvent. Carboxylates and tetrazoles have been studied previously for their abilities to form coordination polymers. ${ }^{3}$ However, research on coordination polymers composed of n-pyridyl-tetrazole derivatives ( $\mathrm{n}$ $=3$ or 4$)$ is limited ${ }^{4}$ while those composed of n-pyridyl-tetrazole derivatives $(n=2)$ are rare. ${ }^{5}$ Our research with pyridyl-tetrazole ligands ${ }^{6}$ has led to derivatives containing either pendant ester or carboxylate groups as organic linkers in MOFs (Scheme 1). The use of carboxylate derivatives are of interest from a structural point of view, since the carboxylate group can adapt various coordination modes including monodentate and bidentate. ${ }^{7}$ The combination of a pyridine ring and a tetrazole ring provide more coordination sites for metals to bind to and could impart rigidity in the final supramolecular structure. In this paper, we report on the reactions of these ligands with copper(II) chloride, including five crystal structures. 


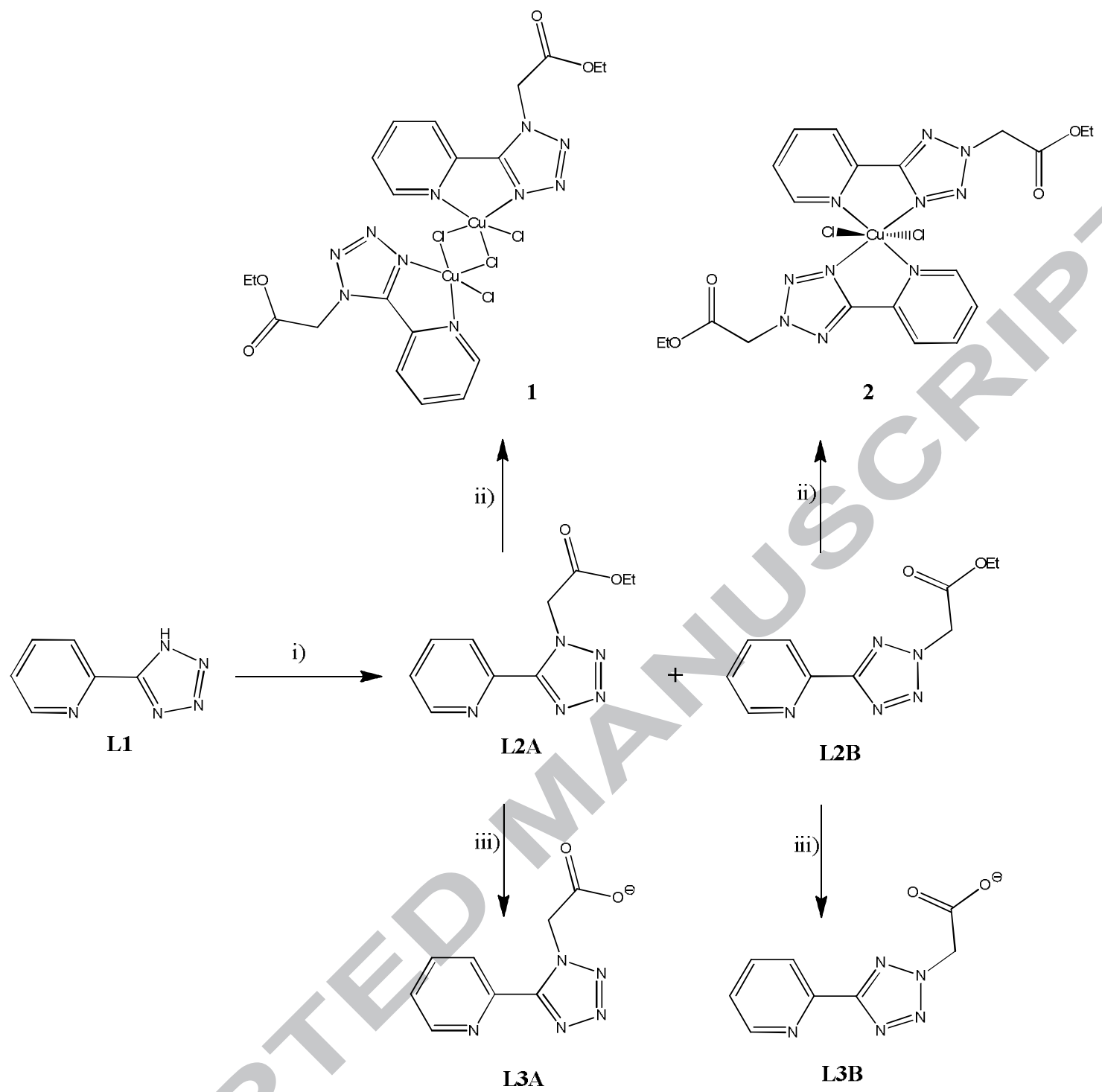

Scheme 1. Reaction conditions: i) ethyl bromoacetate, $\mathrm{K}_{2} \mathrm{CO}_{3}, \mathrm{MeCN}, \Delta, 24 \mathrm{hr}$; ii) $\mathrm{CuCl}_{2} \cdot 2 \mathrm{H}_{2} \mathrm{O}, \mathrm{MeOH}, \Delta, 2 \mathrm{hr}$; iii) $\mathrm{NaOH}, \mathrm{MeOH} / \mathrm{H}_{2} \mathrm{O}, \Delta, 1 \mathrm{hr}$.

\section{Results and Discussion}

\section{Synthesis of ester ligands $\mathbf{L} \mathbf{2 A}$ and $\mathbf{L} \mathbf{2 B}$}

The reaction of 2-(2H-tetrazol-5-yl)pyridine (L1) with ethyl bromoacetate using potassium carbonate as base resulted in the formation of ethyl 2-(5-(pyridine-2-yl)-1H-tetrazol-1yl)acetate (L2A) and ethyl 2-(5-(pyridine-2-yl)-2H-tetrazol-2-yl)acetate (L2B) in a 1:1 ratio, as shown in Scheme 1. The alkylation process at either the $1-N$ or $2-N$ positions is similar to 
what we have previously reported in the literature. ${ }^{7 b, 7 \mathrm{c}}$ Column chromatography was used to separate the two products. In both cases, the loss of the $\mathrm{CH}_{2} \mathrm{Br}$ signal and the appearance of a triplet at $5.74 \mathrm{ppm}$ for the $1-N$ compound $\mathbf{L 2 A}$ and $5.50 \mathrm{ppm}$ for the $2-N$ compound $\mathbf{L} \mathbf{2} \mathbf{B}$ in the ${ }^{1} \mathrm{H}$ NMR spectra of the products was taken as evidence for the formation of the correct products. Furthermore, L2A gave a signal at $\sim 152$ ppm, while L2B gave a signal at $\sim 160$ ppm in their ${ }^{13} \mathrm{C}$ NMR spectra, indicative of the formation of 1,5- and 2,5-disubstituted tetrazole rings. ${ }^{7 \mathrm{a}, 8}$

Synthesis and characterisation of copper complexes of $\mathbf{L} 2 \boldsymbol{A}$ and $\mathbf{L} \mathbf{2 B}$

The reaction of $\mathbf{L 2 A}$ or $\mathbf{L 2 B}$ with $\mathrm{CuCl}_{2} \bullet 2 \mathrm{H}_{2} \mathrm{O}$ in a 1:1 metal:ligand ratio in methanol resulted in highly coloured solutions, which were allowed to stand for several days. Green crystals of $\left[\mathrm{Cu}(\mathbf{L 2} \mathbf{A}) \mathrm{Cl}_{2}\right]_{2}$ (1) and blue crystals of $\mathrm{Cu}(\mathbf{L} 2 \mathbf{B})_{2} \mathrm{Cl}_{2}$ (2) crystallised from the respective solutions on standing (Scheme 1). The IR spectra of both $\mathbf{1}$ and $\mathbf{2}$ were obtained and compared with their respective starting ligands. It was observed that the carbonyl vibration remained unchanged on going from the ligand to the metal complex, which would suggest that the copper ion is not bonded to the ester group but is instead bonded through the nitrogen atoms of the pyridine and tetrazole rings, as had been observed in other pyridinetetrazole systems previously reported. ${ }^{7 b, 7 c}$ Elemental analyses of $\mathbf{1}$ and $\mathbf{2}$ suggested a 1:1 and a 1:2 metal to ligand ratio in each case. The copper complexes have a magnetic moment of 1.7 B.M. and 2.2 B.M. per copper atom, indicative of the presence of copper(II) in the complexes. Previously reported magnetic moments for complexes containing pyridyltetrazole ligands have been both high in value and high-spin in nature. ${ }^{7 b, 9}$ The single crystal structures of both were established by X-ray crystallography. Crystallographic data for all structures are presented in Table $1(\mathrm{SI})$.

\section{Crystal structures of $\mathbf{1}$ and $\mathbf{2}$}

Compound 1 crystallises in the triclinic space group $P^{-} 1$ and established the 1:2 nature of the molecule (Fig. 1a,b). The molecular structure consists of a dichloro-bridged dimeric $\{\mathrm{Cu}(\mathrm{II})(\mu-\mathrm{Cl}) \mathrm{Cl}\}_{2}$ unit, with the coordination sphere about each $\mathrm{Cu}(\mathrm{II})$ atom comprising one pyridine $\mathrm{N}$ atom, one tetrazole $\mathrm{N}$ atom and three chlorine atoms (two of which are $\mu-\mathrm{Cl}$ bridging chlorines). The dimeric complex lies on a crystallographic inversion centre which 
lies at the centre of the $[\mathrm{Cu}(\mathrm{II})(\mu-\mathrm{Cl}) \mathrm{Cl}]_{2}$ core and this structure is similar to the previously reported copper dimer complex $\left[\mathrm{Cu}(\mathrm{L}) \mathrm{Cl}_{2}\right]_{2}$ where ligand $\mathrm{L}=2$-(2-(6-bromohexyl)- $2 \mathrm{H}$ tetrazol-5-yl)pyridine. $^{7 \mathrm{~b}}$ The coordination geometry of each copper(II) centre is a distorted square pyramidal, with the Addison parameter, $t=0.22$ (where $t=0$ for ideal squarepyramidal and $t=1$ for ideal trigonal-bipyramidal). ${ }^{10}$
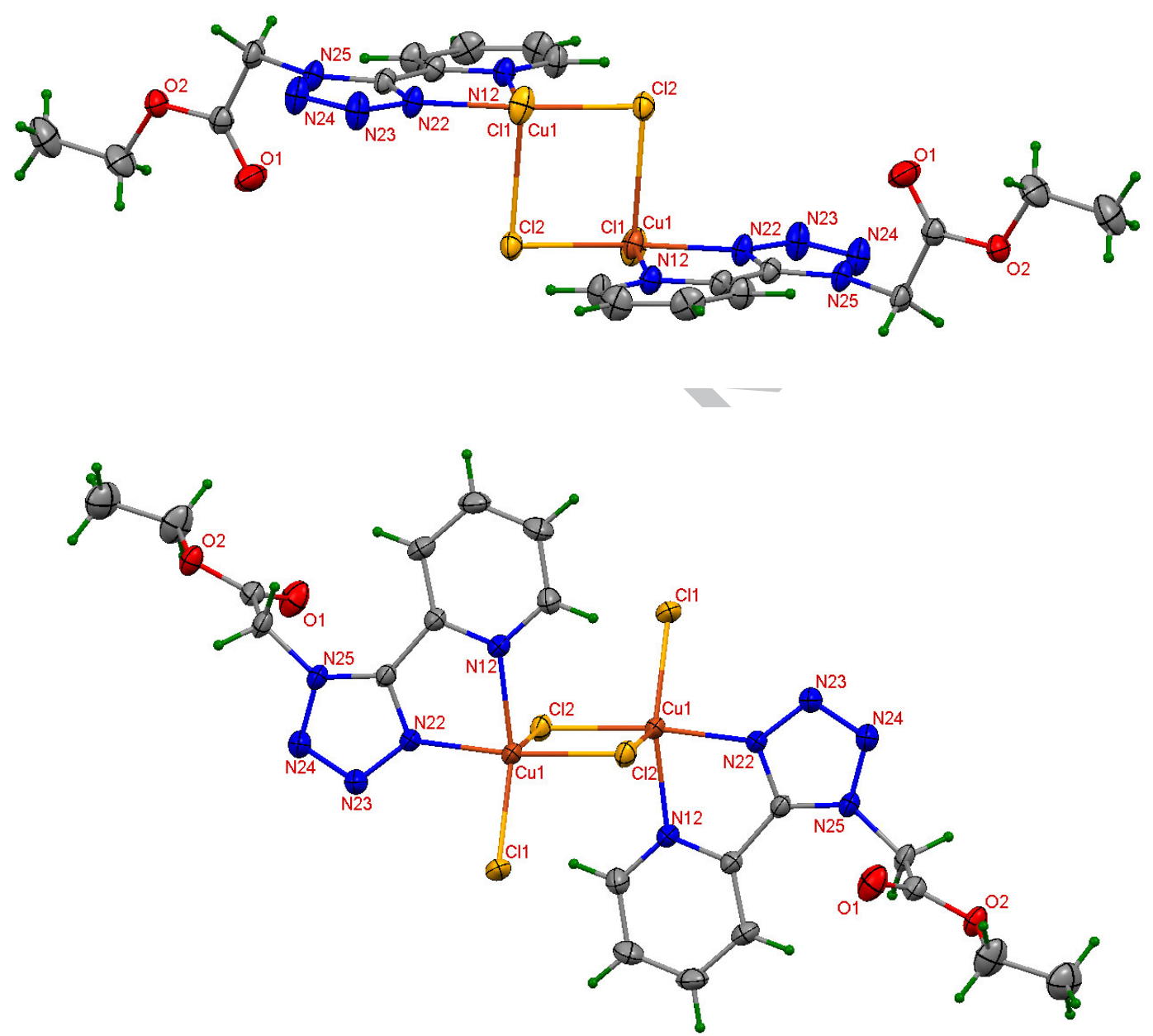

Fig. 1. Two views of the molecular structure of $\mathbf{1}$ highlighting the square pyramidal $\mathrm{Cu}$ geometry and $[\mathrm{Cu}(\mathrm{II})(\mu-\mathrm{Cl}) \mathrm{Cl}]_{2}$ unit with displacement ellipsoids at the $30 \%$ probability level.

Each pyridyl-tetrazole ligand binds to the copper(II) atom through one tetrazole $\mathrm{N}$ atom at the $1-N$ site of the tetrazole ring and through the pyridyl $\mathrm{N}$ atom, generating a five-membered chelate ring. As previously observed, the 5-membered tetrazole ring is slightly twisted with respect to the 6-membered pyridyl ring at an angle of $9.9(2)^{\circ}$ with the 6 atom co-planar ester 
group almost orthogonal with the tetrazole-pyridine ligand at $83.79(7)^{\circ} .^{7 b, 9,11}$ In the central core, the four-membered $\mathrm{Cu}_{2} \mathrm{Cl}_{2}$ ring is planar and is comparable with those of related dichloro-bridged dimers in the literature. ${ }^{7 b, 12,13}$ Analysis of 52 structures on the CSD with the $\left[\left(\mathrm{C}_{6} \mathrm{H}_{4} \mathrm{NCN}\right) \mathrm{Cu}(\mathrm{II})(\mu-\mathrm{Cl}) \mathrm{Cl}\right]_{2}$ core shows that the vast majority of $\mathrm{Cl}-\mathrm{Cu}-\mathrm{Cl}$ and $\mathrm{Cu}-\mathrm{Cl}-\mathrm{Cu}$ angles are in the ranges $90-115^{\circ}$ and $82-98^{\circ}$. For the bond lengths, the majority lie close to mean values of 2.25(1) $\AA$ and 2.28(1) $\AA$ (with clusters at $2.45 \AA$ and $2.70 \AA$ for the longer of the $\mu-\mathrm{Cl}-\mathrm{Cu}$ distances) and 2.03(1) $\AA$ for $\mathrm{Cl}-\mathrm{Cu}, \mu-\mathrm{Cl}-\mathrm{Cu}$ and $\mathrm{Cu}-\mathrm{N}$ (pyridinyl and other-N). ${ }^{13}$ There are no classical interactions and the three intermolecular interactions of note are C$\mathrm{H}$... Cl contacts which are $c a .0 .30 \AA$ shorter than the sum of the contact radii for $\mathrm{H}$ and $\mathrm{Cl}$ $(\approx 2.95 \AA)$. The three interactions link dimers into sheets that are parallel with the (001) plane. There are no inter-sheet contacts of note.

Blue crystals of 2 were obtained from the reaction between $\mathrm{CuCl}_{2} \bullet 2 \mathrm{H}_{2} \mathrm{O}$ and $\mathbf{L 2 B}$. The complex lies on a crystallographic inversion centre (Fig. 2) with the copper(II) centre adopting a slightly distorted octahedral coordination geometry as a result of the pyridyltetrazole ligands occupying the equatorial plane and the chloride anions occupying the axial positions. The structure is similar to that reported by Yang and co-workers ${ }^{11 \mathrm{~d}}$ of a zinc complex formed from the reaction of $\mathrm{ZnCl}_{2}$ with 5-(2-pyridyl)tetrazole-2-acetic acid. The major difference between both structures is that in our compound $\mathbf{2}$, the ligand is neutral whereas in the case of the zinc complex, the 5-(2-pyridyl)tetrazole-2-acetic acid ligand is anionic. In 2, however, there is a slight twist within the ligand so that the planes of the tetrazole and pyridine rings form a dihedral angle of $5.38(13)^{\circ}$; the five atom co-planar ester group is $77.93(5)^{\circ}$ to the 11 -atom ligand ring atoms (the terminal $\mathrm{CH}_{3}$ is not included). The coordination at the $\mathrm{Cu}$ centre is asymmetric with the $\mathrm{Cu}-\mathrm{N}$ bond lengths differing by $0.44 \AA$ (the $\mathrm{Cu}-\mathrm{N}_{\text {tetrazolyl }}$ bond length in $\mathbf{1}$ is $\cong 2.0 \AA$ ). Differences can be ascribed to the 5 vs 6coordination and the more symmetrical nature of $\mathbf{1}$ as compared to $\mathbf{2}$ at the $\mathrm{Cu}$ centre. There are no classical hydrogen bonds in $\mathbf{2}$ and the important intermolecular contacts are the three $\mathrm{C}-\mathrm{H}$... Cl and two $\mathrm{C}-\mathrm{H}$...O per asymmetric unit. In fact the $\mathrm{Cu}-\mathrm{Cl}$ group resides in a pocket with three $\mathrm{C}-\mathrm{H}$ moieties directed towards the chloride ligand; however the $\mathrm{H}$... $\mathrm{Cl}$ distances are $0.2 \AA$ longer than observed in $\mathbf{1}$. 


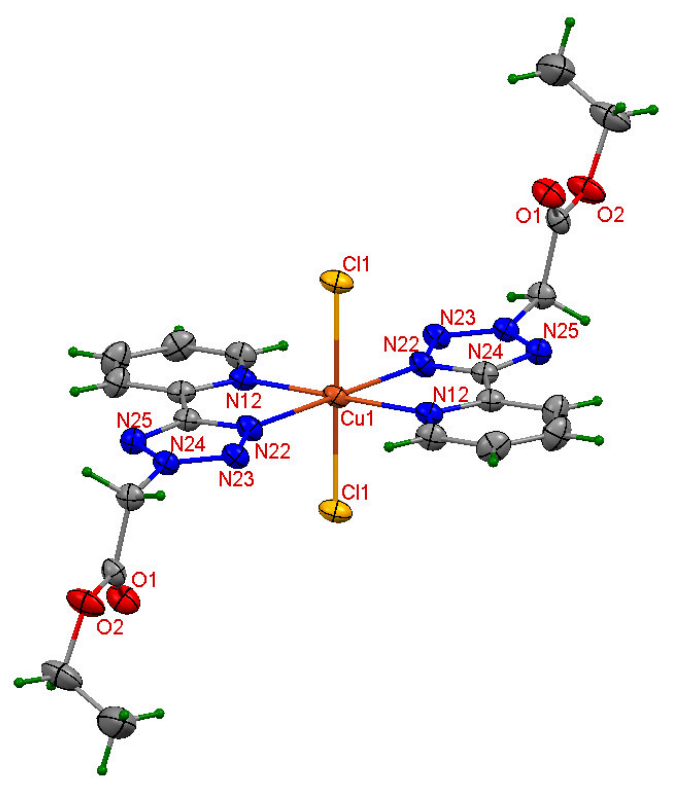

Fig. 2 The molecular structure of 2 with displacement ellipsoids at the $30 \%$ probability level.

Synthesis of carboxylate ligands $(\mathbf{L} 3 \boldsymbol{A} \& \mathbf{L} 3 \boldsymbol{B})$ and their copper complexes 3-6

Recent work by Zhou and co-workers ${ }^{14}$ using the ligand tetrazole-5-ethyl acetate with copper(II) chloride dihydrate in sodium hydroxide solution resulted in the formation of the polymeric coordination complex $\left[\mathrm{CuNa}_{2}(\mathrm{tza})_{2} \cdot\left(\mathrm{H}_{2} \mathrm{O}\right)_{4}\right]_{n}$ (tza $=$ tetrazole-5-acetato) which formed a 2D layer structure containing 4-, 5-, 6- and 14-membered rings. Two important features of this complex were both the loss of the ester group and the incorporation of the sodium ion into the polymer on complexation. This raised the question on whether the ligands $\mathbf{L 2} \mathbf{A}$ and $\mathbf{L 2 B}$ would behave in a similar manner, if the complexation reaction with copper chloride was carried out in $\mathrm{NaOH}$ solution.

The conversion of an ester to a carboxylic acid is easily achieved using $\mathrm{NaOH}$ in methanol. ${ }^{15}$ This reaction would have a two-fold benefit: i) it would give a carboxylate group on the tetrazole unit and this carboxylate could then become involved in potential inter- and intramolecular interactions, and ii) as there were sodium ions in solution, these ions could possibly interact with the carboxylate groups to give metal-organic frameworks (MOFs). So, the reactions of $\mathbf{L 2 A}$ and $\mathbf{L 2 B}$ with $\mathrm{NaOH}$ were carried out in a mixture of methanol and 
water (as in Scheme 1) before adding a solution of $\mathrm{CuCl}_{2} \bullet 2 \mathrm{H}_{2} \mathrm{O}$ in methanol to each reaction, without isolating the new ligands.

In the initial reaction, $\mathrm{NaOH}$ in distilled water was added to a solution of $\mathbf{L 2 A}$ in methanol and the resulting solution was refluxed for 1 hour. After this time, the methanolic copper chloride solution was added to the hot solution and immediately a blue solid precipitated from solution. Elemental analysis of the blue solid suggested that there was no sodium present in the complex and that the empirical formula of the compound was $\mathrm{C}_{8} \mathrm{H}_{6} \mathrm{CuN}_{5} \mathrm{O}_{2}(3)$. This blue solid was then dissolved in water and allowed to stand for several days in order to get crystals suitable for X-ray crystallography. After several days, blue crystals of $\mathbf{3}$ were obtained.

The reaction was repeated with the reaction conditions changed slightly in order to try and get better solubility of the material and also to see if it was possible to get sodium ions into the final molecule, in a manner similar to Zhou and co-workers. ${ }^{14}$ The ligand L2A was dissolved in a mixture of distilled water and methanol (10:1 ratio) and to this was added the $\mathrm{NaOH}$, after which the solution was heated to reflux for 1 hour. The copper salt was added as an aqueous solution to the hot solution. The resulting solution was allowed to stand for several days from which blue block-like crystals (4) precipitated slowly. The elemental analyses of these crystals showed that no sodium was present in this complex either and gave the empirical formula $\mathrm{C}_{16} \mathrm{H}_{14} \mathrm{CuN}_{10} \mathrm{O}_{5}$. Crystallographic studies of both $\mathbf{3}$ and $\mathbf{4}$ were undertaken.

Two similar complexation reactions to those carried out with $\mathbf{L 2 A}$ were carried out with L2B. The new ligand $\mathbf{L 3 B}$ was used immediately on formation and reaction with copper(II) chloride in both solvent systems resulted in the formation of two blue complexes $\mathbf{5}$ and $\mathbf{6}$. The elemental analyses of 5 gave an empirical formula of $\mathrm{C}_{16} \mathrm{H}_{12} \mathrm{Cu}_{3} \mathrm{~N}_{10} \mathrm{O}_{6}$ while that of $\mathbf{6}$ gave one of $\mathrm{C}_{16} \mathrm{H}_{16} \mathrm{CuN}_{10} \mathrm{O}_{6}$. A crystallographic study of 6 was also undertaken.

\section{Crystal structures of $\mathbf{3}, \mathbf{4} \& \mathbf{6}$}

Crystal 3 crystallises in the triclinic space group P-1 (No. 2) and the complex resides on a crystallographic inversion centre and the complex is shown in Fig. 3 (the asymmetric unit 
contains a $\mathrm{Cu}$ atom and the ligand). Each copper(II) centre is in an octahedral geometry, being coordinated by four nitrogen atoms of two L3A ligands in the equatorial plane and two axial oxygen atoms from two other L3A ligands lying above and below the copper(II) ion (Fig. 4). The molecule is neutral overall since the charges on the copper ion are balanced by the two singly charged anionic carboxylate ligands. Thus, each L3A ligand (that exhibits a considerable twist of $15.0(3)^{\circ}$ between the pyridine/tetrazole rings) is involved in bonding one copper ion through the pyridine $\mathrm{N}$ atom and the tetrazole $\mathrm{N} 1$ atom, in a bidentate manner, while also bonding to a second copper ion through the $\mathrm{O} 2$ oxygen atom of the carboxylate group in a unidentate fashion. This method of bridging is common in carboxylate complexes. ${ }^{3,16}$ Only one of the two carboxylate oxygen atoms are involved in bonding within the molecule (polymeric chain) and this can be observed in the $\mathrm{C}-\mathrm{O}$ and $\mathrm{C}=\mathrm{O}$ bond lengths in the carboxylate ligand.

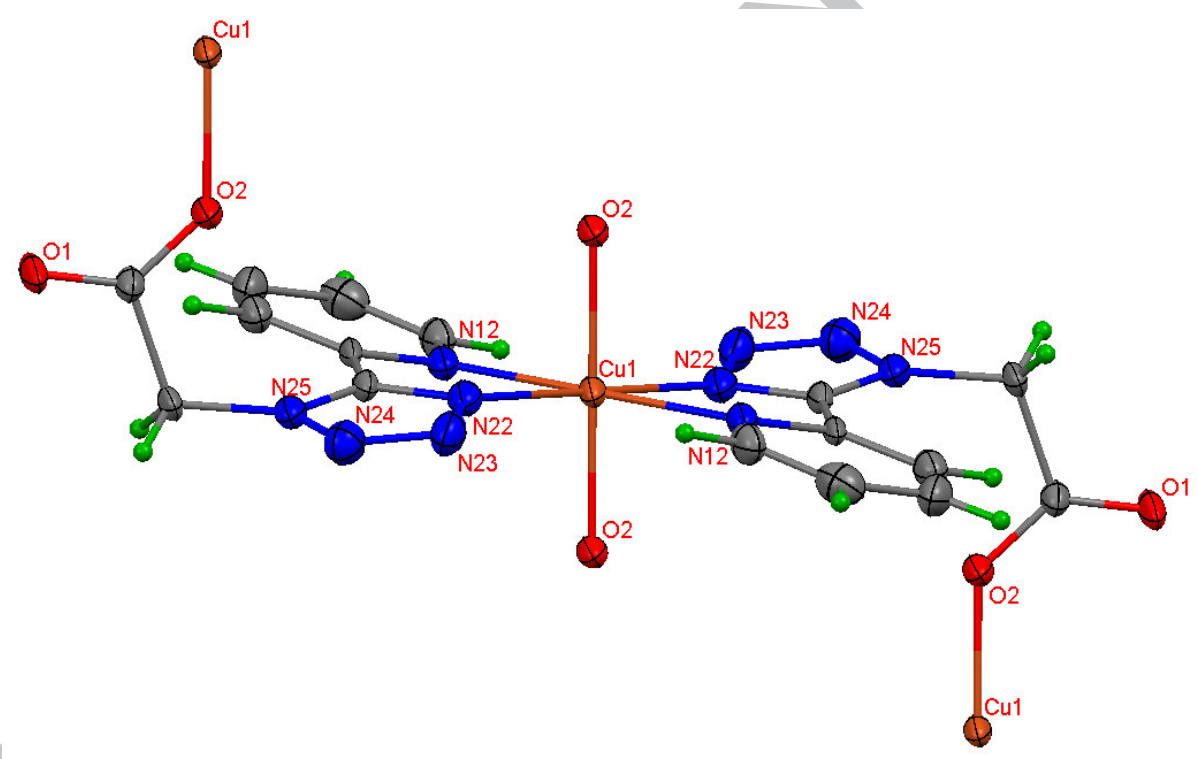

Fig. 3 The molecular structure of $\mathbf{3}$ with displacement ellipsoids at the $30 \%$ probability level and highlighting the $\mathrm{Cu}-\mathrm{O}_{\text {carboxylate }}$ binding.

The partial packing diagram in Fig. 4 shows that the complex is oriented in a stepwise manner with interactions between the copper ions and the carboxylate groups only occurring along the step direction along the [100] direction. No strong interactions are observed between the 1-D steps but they dovetail clearly by a reciprocal arrangement of weak C-H...O interactions involving symmetry-related $\mathrm{C} 1$ and $\mathrm{C} 16$ atoms with $\mathrm{O} 1$ of two neighbouring 
chains. This gives rise to weakly connected sheets parallel to the ab plane or (001) plane. There are no interactions of consequence linking the sheets.

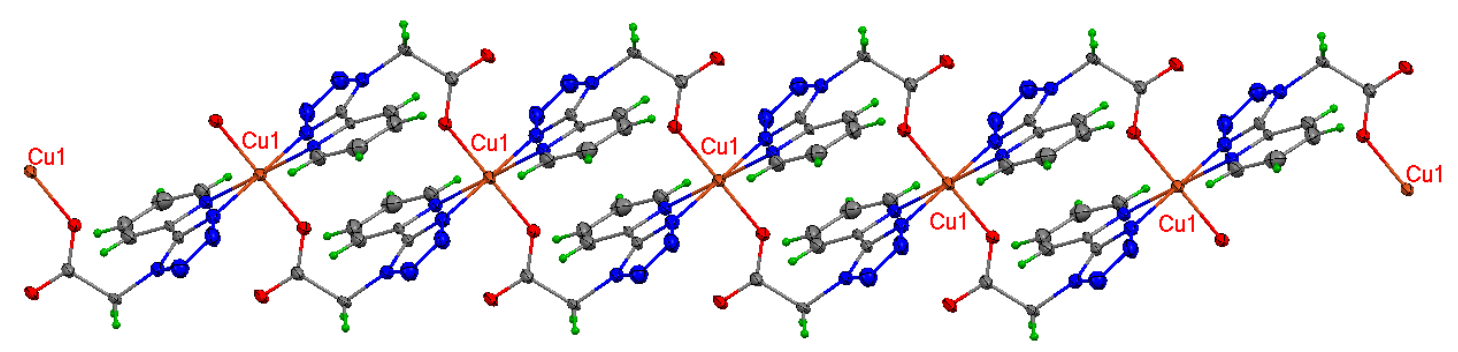

Fig. 4 The 1-D chain formation in $\mathbf{3}$ (with displacement ellipsoids at the $30 \%$ probability level) highlighting the polymeric nature of the $\mathrm{Cu}-\mathrm{O}_{\text {carboxylate }}$ binding.

Compound 4 also crystallises in the $P^{-} 1$ space group and the dimeric molecular complex (including the asymmetric unit comprising one $\mathrm{Cu} 1$ metal centre, one water molecule $\mathrm{O} 1 \mathrm{~W}$ and two L3A ligands) is shown in Fig. 5. The complex is built up about inversion centres midway between the two $\mathrm{Cu}$ metal centres. Each copper(II) ion is in a distorted octahedral geometry and a key feature of the molecular structure is that one of the L3A ligand $(\mathrm{O} 1 / \mathrm{O} 2 / \mathrm{N} 12 / \mathrm{N} 22)$ behaves in both a bridging (using O2/N12/N22) and chelating (via $\mathrm{N} 12 / \mathrm{N} 22)$ fashion while the second L3A ligand (O3/O4/N32/N42) is only involved in binding through its carboxylate group; the remaining $\mathrm{N}$ donors at most only engage in hydrogen bonding. The behaviour is reminiscent of the behaviour of bisphosphines whereby they can bind to metals in typically in bridging, chelating or just binding through one of the phosphorus atoms. 


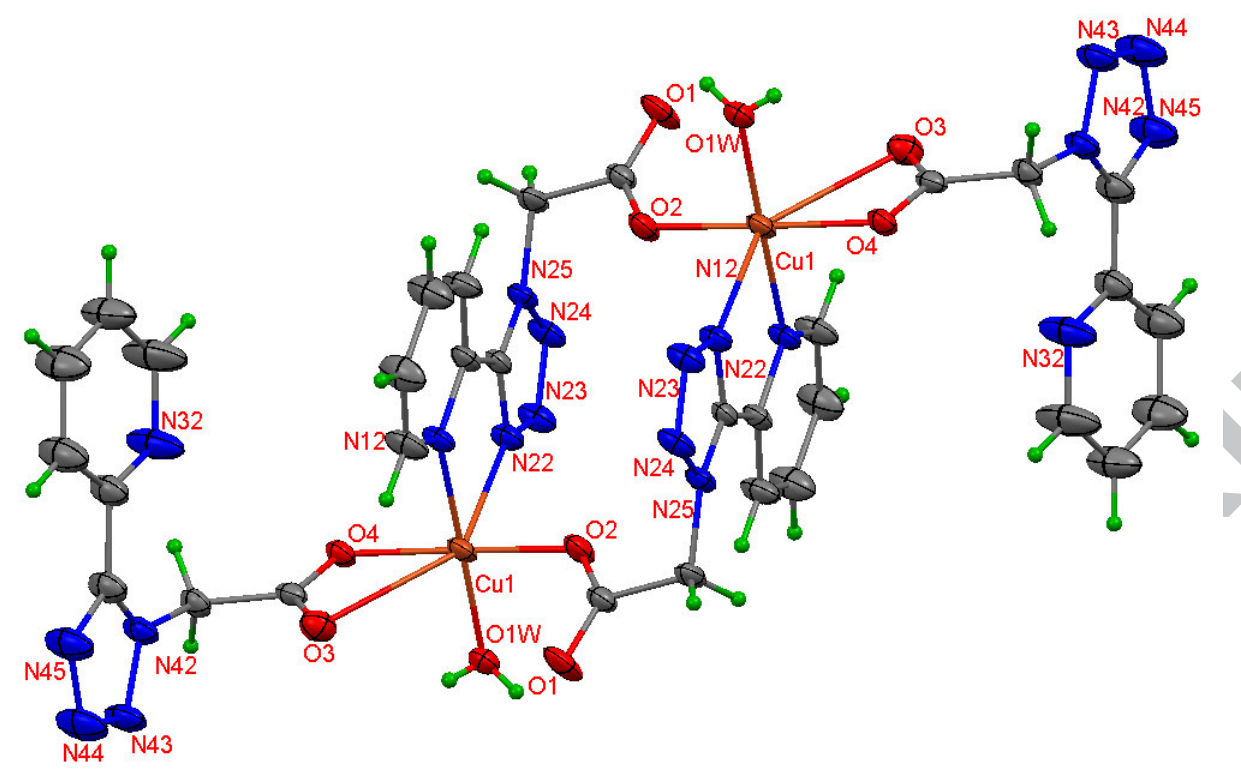

Fig. 5. The molecular structure of $\mathbf{4}$ with displacement ellipsoids at the $30 \%$ probability level.

The coordination sphere around each copper ion consists of $(i)$ a pyridine nitrogen atom and a tetrazole $\mathrm{N}$ atom from an $\mathbf{L 3 A}$ ligand, (ii) one oxygen atom from the carboxylate group of a second L3A ligand, (iii) two oxygen atoms from the carboxylate group of a third L3A ligand, and (iv) a water molecule that completes the hexa-coordinate geometry. The geometry can be viewed as a combination of a central dimeric core comprising two $\mathrm{Cu}$ atoms chelated (via $\mathrm{N}$... N)/bridged ( $\left.\mathrm{O}_{\text {carboxylate }}\right)$ by two L3A ligands and capped by the water molecule and bidentate carboxylate of the third L3A ligand (which contains a short intramolecular C$\mathrm{H} . . . \mathrm{N} 32$ interaction involving the pyridyl $\mathrm{N}$ atom). The L3A ligands are not planar, and has been noted previously exhibits a measure of interplanar distortion and exhibits dihedral angles of $7.4(2)^{\circ}$ and $6.8(3)^{\circ}$ between the planes of the pyridine and tetrazole rings. From Fig. 5 , each carboxylate group present in the structure coordinates in either a unidentate $(\mathrm{O} 2)$ or bidentate manner (using $\mathrm{O} 3, \mathrm{O} 4)$. As a result of coordination modes adopted by the carboxylate groups, niches of various sizes are formed within the structure and these are either 16 or 22 atoms in size (Fig. 6). 


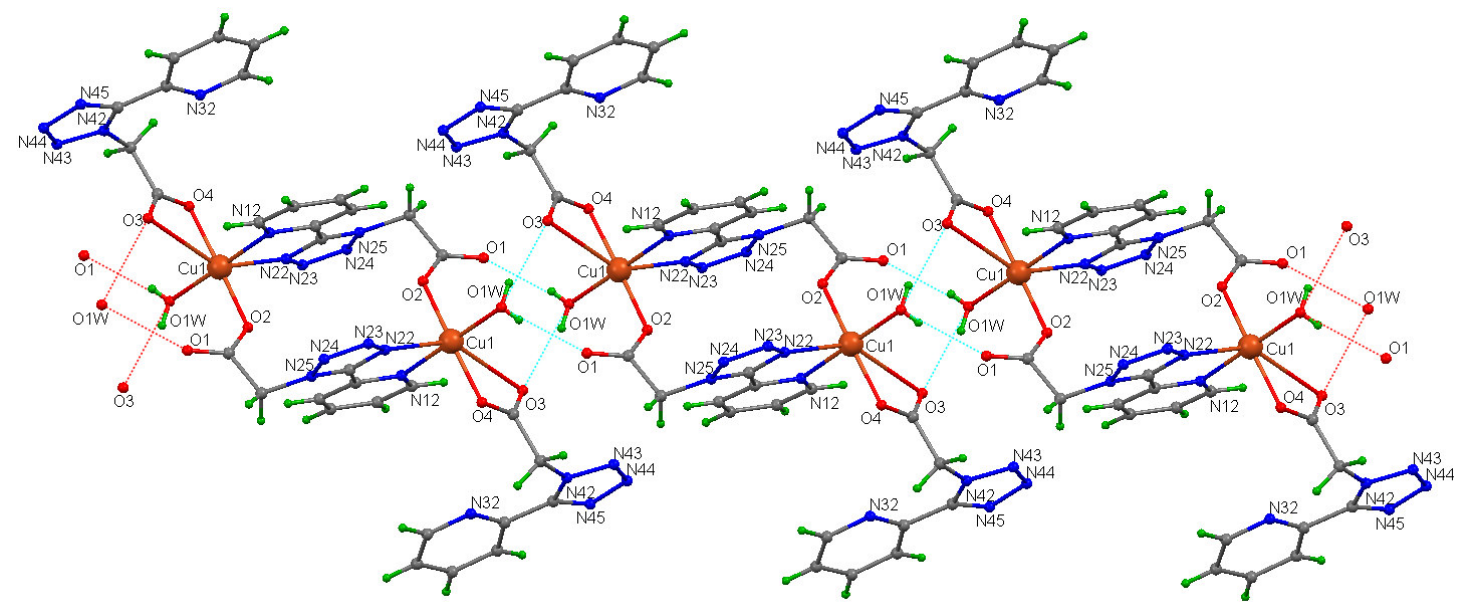

Fig. 6. The primary hydrogen bonding involving O1W and linking molecules of 4.

The coordination of the water molecule to the copper(II) metal centre is the most obvious difference between the structures of $\mathbf{3}$ and $\mathbf{4}$ and its effect on the resulting crystal structure. The water molecule participates in strong hydrogen bonding involving reciprocal water $\mathrm{O} 1 \mathrm{~W} \ldots \mathrm{O}_{\text {carboxylate }}$ hydrogen bonds about inversion centres in an inorganic complex that is rich in hydrogen bond acceptors (e.g. $\mathrm{O}=\mathrm{C}, \mathrm{N})$; the intermolecular $\mathrm{O} \ldots \mathrm{O}$ distances are 2.680(5) and $2.736(5) \AA$. The strong hydrogen bonding between dimers thus generates a hydrogen bonded chain along the $b$-axis direction. Hydrogen bonded chains are further linked into a 2$\mathrm{D}$ network of hydrogen bonds by a combination of several $\mathrm{C}-\mathrm{H} \ldots \mathrm{O} / \mathrm{N}$ interactions and parallel with the (100) plane (Fig. 7a,b). 


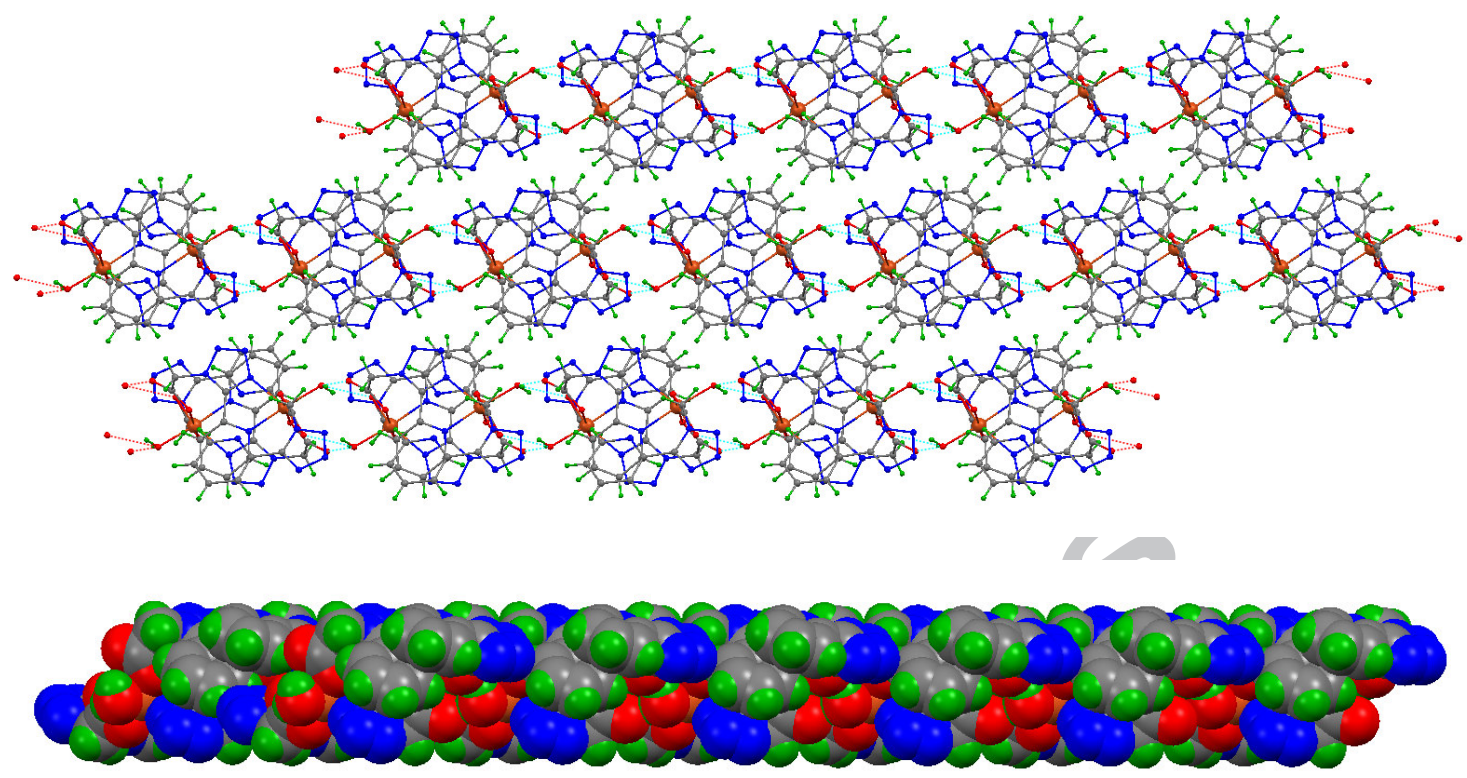

Fig. 7. (a) A view of hydrogen bonding between molecules of 4 in the three hydrogen bonded chains propagating along the $b$-axis direction and (b) a side-view of the 2-D sheet with atoms depicted as their van der Waals spheres.

Compound 6 crystallises in the monoclinic system in the $P 2_{1} / c$ space group and molecular structure and primary hydrogen bonding system depicted in Fig. 8. Each copper(II) ion resides on a crystallographic inversion centre and is in a octahedral geometry, resulting from the coordination of two L3B ligands through the pyridine nitrogen atom and one tetrazole $\mathrm{N}$ atom from each ligand and two water molecules. Each L3B ligand is negatively charged through the loss of a carboxylate proton, thereby making the overall molecule neutral and both carboxylate $\mathrm{C}-\mathrm{O}$ bond lengths are similar in bond length (intermediate between single and double bonding). Each water molecule is involved in two hydrogen bond interactions with the carboxylate groups of two different L3B ligands, as shown in Figures 8, 9. The $R_{4}^{4}(12)$ O-H...O arrangement involving two water molecules and two carboxylate groups from four different molecules can be seen in Fig. 9. This strong O-H...O hydrogen bonding then creates a large network of interactions throughout the structure with molecular niches that are too small to contain a solvent molecule, resulting in the partial framework structure as shown in Figure 9. Here, the pockets containing the copper(II) ions can be seen within the 
honeycomb structure formed by the organic matrix. Future design will expand the organic framework to expand and connect these niches.

\section{EPR spectra of 1-6}

X-band EPR spectra were recorded of 1-6 as powders at room temperature, see ESI Figures S1-S6. As the spectra revealed no signature of metal-metal interactions, the spectra were fitted $^{18}$ to the spin Hamiltonian

${ }^{\wedge} H=A x^{\wedge} S x^{\wedge} I x+A y^{\wedge} S y^{\wedge} I y+A z^{\wedge} S z^{\wedge} I z+\_B\left(g x^{\wedge} S x B x+g y \wedge S y B y+g z \wedge S z B z\right)$

being appropriate for mononuclear $\mathrm{Cu}^{2+}$ spin systems with quantum numbers $(S ; I)=(1 / 2$, $3 / 2$ ). The values of the spin Hamiltonian parameters as extracted from the spectra are reported in the captions to Figures S1-S6. Despite the rather large bandwidths (>50 G) in the experimental spectra, the $g$ factors could be extracted from the spectra, of which 1, 2, and 4 reflected approximate axial symmetry with $g_{z}>\left(g_{x} \sim g_{y}\right)$. On the other hand, $\mathbf{3}, \mathbf{5}$ and $\mathbf{6}$ exhibit three clearly different $g$ factors, see captions to Figures S1-S6. The parameters $A_{x} ; A_{y}$ could not be determined from the broad lines, and $A_{z}$ could be reliably estimated from compounds $\mathbf{1}, \mathbf{3}$, and $\mathbf{4}$, only. No solution, or frozen solution, spectra were recorded as DMSO was the only solvent in which all samples were soluble and it was believed that this solvent would replace the water molecules in the structure resulting in spectra with little or no relevance for the solid samples. 


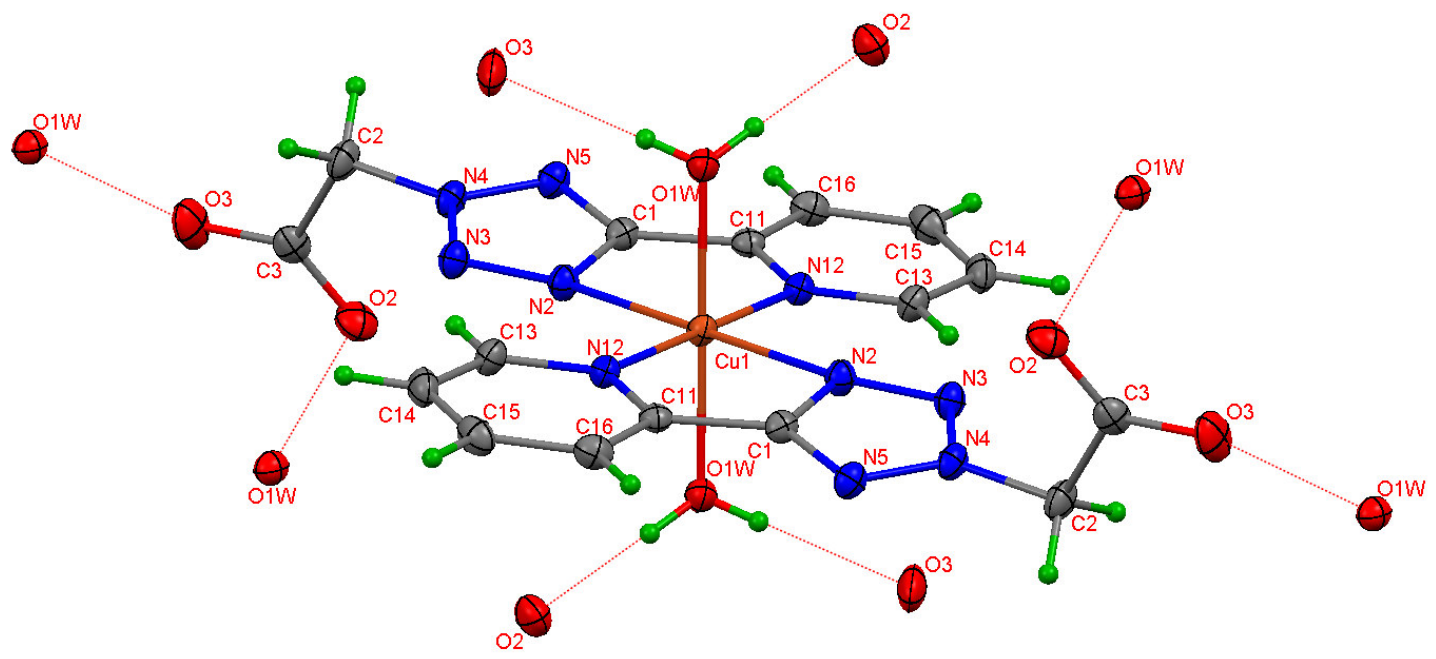

Fig. 8. The molecular structure of 6 with displacement ellipsoids at the $30 \%$ probability level including the primary intermolecular O-H...O hydrogen bonds.

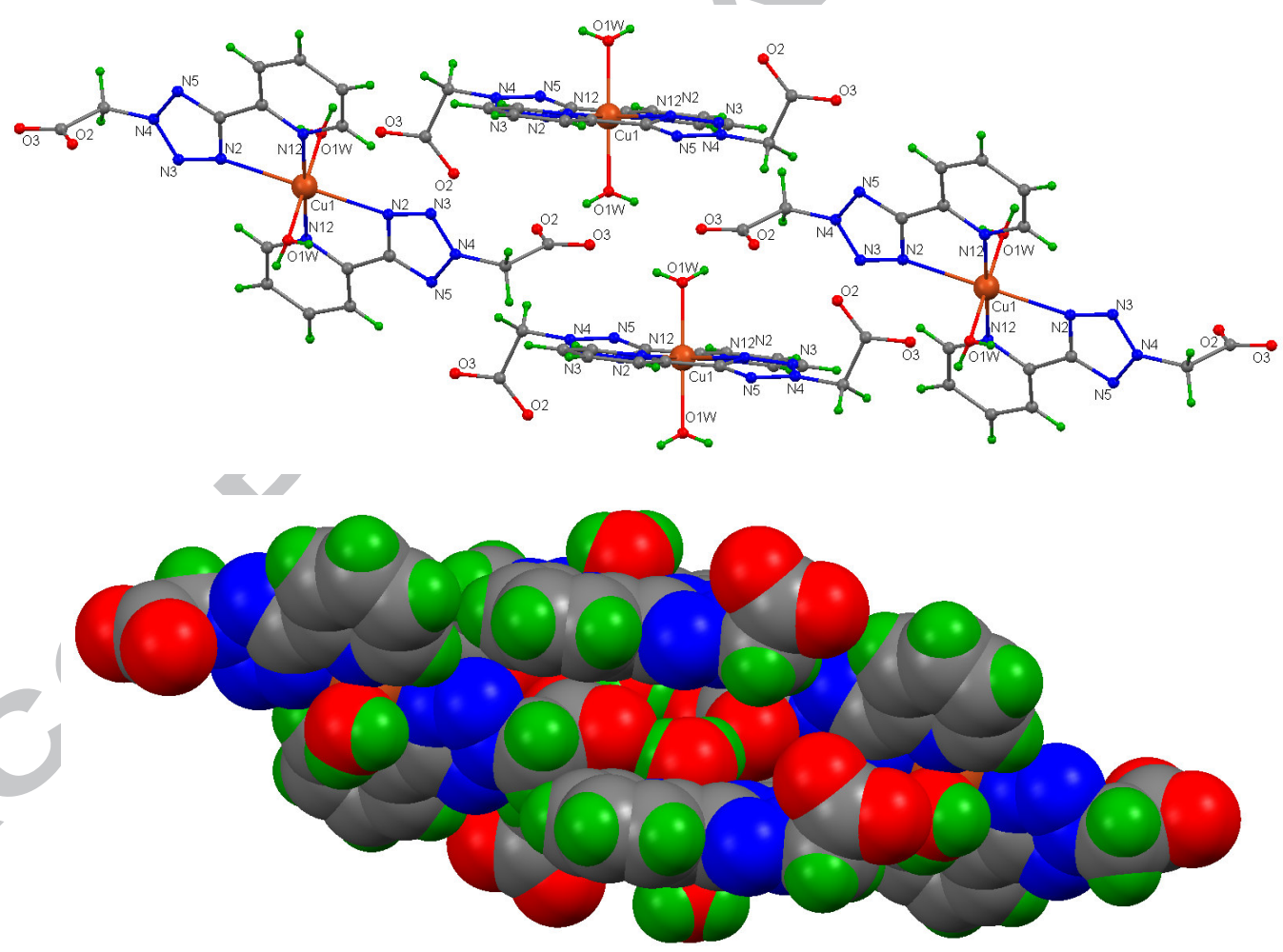

Fig. 9. Part of the intricate intermolecular O-H...O hydrogen bonding in structure of 6 with (a) displacement ellipsoids at the $30 \%$ probability level and (b) atoms as their van der Waals spheres. 


\section{Fluorescence spectroscopy}

The fluorescence spectra of the free ligands L2A and L2B and compounds 1-6 were studied in aqueous solution at room temperature. The concentration used in each case was $12 \mu \mathrm{M}$. The emission spectrum of the free ligand L2A exhibited emission bands at ca. $452 \mathrm{~nm}$ with $\lambda_{\mathrm{ex}}=272 \mathrm{~nm}$ (see Fig. 10). The related complexes 1, 3 and $\mathbf{4}$ exhibited decreased luminescence intensities relative to the free ligand with complex $\mathbf{1}$ causing considerable quenching of the fluorescence signal. The quenching in all cases is attributed to copper(II) coordination. The quenching is not as dramatic for complexes $\mathbf{3}$ and $\mathbf{4}$, but then the ligand used in those complexes is not the ester ligand $\mathbf{L 2} \mathbf{A}$, so a direct comparison cannot be made. Furthermore, compared with the emission spectrum of $\mathbf{L 2 A}$, a large blue shift of $94 \mathrm{~nm}$ in $\mathbf{1}$ is observed, with smaller shifts of 7 and 39 nm observed for 3 and 4.

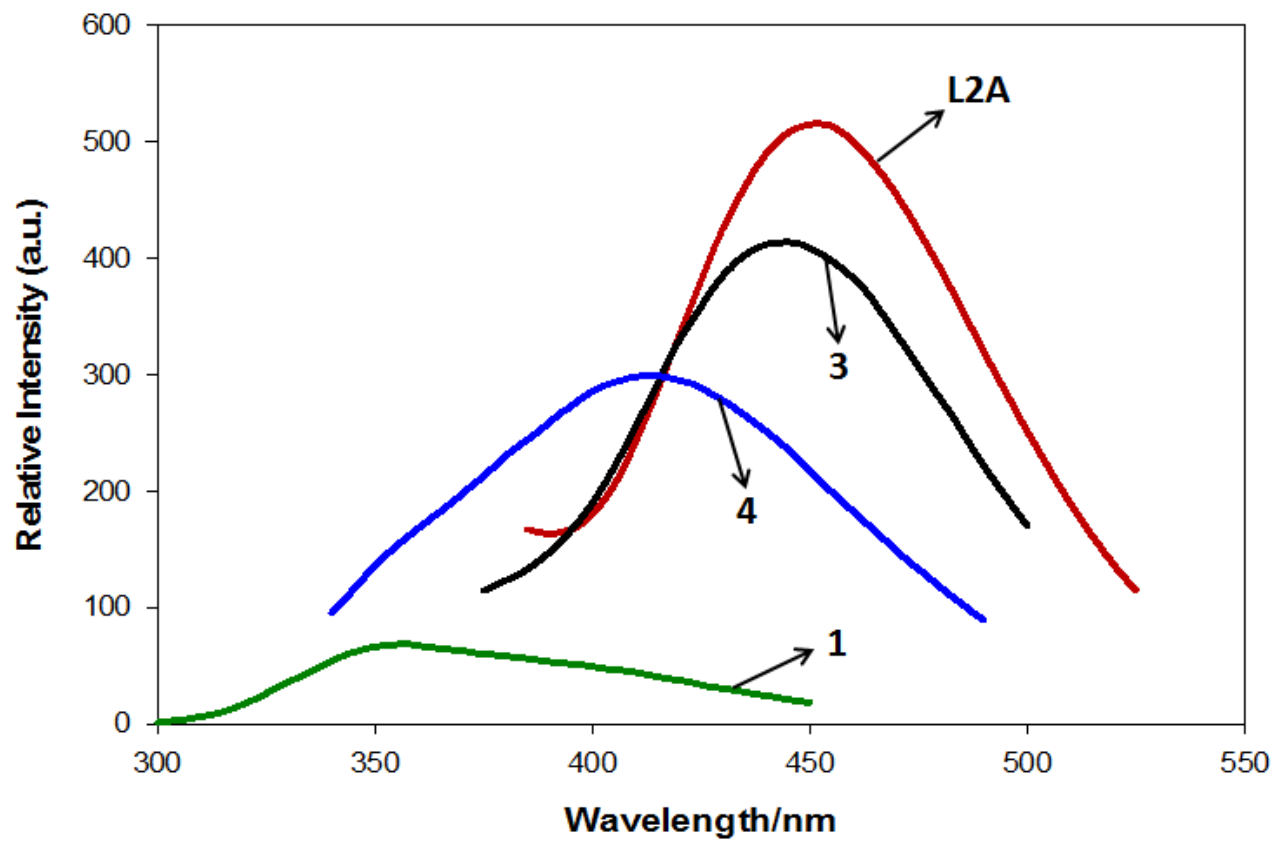

Fig. 10. Fluorescence emission spectra of $\mathbf{L 2 A}(12 \mu \mathrm{M}$, red), 1 (12 $\mu \mathrm{M}$, green), 3 (12 $\mu \mathrm{M}$, black) and 4 (12 $\mu \mathrm{M}$, blue) in $\mathrm{H}_{2} \mathrm{O}$; the excitation wavelengths were 272, 236, 260 and 268 $\mathrm{nm}$ respectively.

Interestingly, whilst exhibiting intense excitation spectrums, the free ligand L2B and related complexes 2, 5 and $\mathbf{6}$ showed little or no emission, indicating that they undergo a different relaxation pathway to the $\mathrm{N} 1$ derivatives. 


\section{Conclusions}

In summary, this study reveals the coordination patterns of the title ligand in its ester and carboxylate form with $\mathrm{Cu}$ (II) ions. We present six novel coordination complexes 1-6. The structures of these complexes has been established by single-crystal X-ray diffraction analysis and also characterised by IR and elemental analysis. Whilst $\mathbf{1}$ and $\mathbf{2}$ are independent complexes, $\mathbf{3}$ and $\mathbf{4}$ are coordination polymers due to coordination of carboxylate oxygen atoms as well as pyridine and tetrazole nitrogen atoms. 3 is characteristic of a $1 \mathrm{D}$ chain-like structure, whereas 6 forms more complex 3D supramolecular networks by intermolecular hydrogen bonds. The solution state emission spectra of the polymers $\mathbf{3}$ and $\mathbf{4}$ showed quenching of the emission band compared to that of the free ligands, whereas $\mathbf{5}$ and $\mathbf{6}$ showed no such effect. Further fluorescence studies are being undertaken to investigate this phenomenon. Evaluation of potential porosity features of the polymers/frameworks also requires more intensive investigation.

\section{Experimental}

${ }^{1} \mathrm{H}$ and ${ }^{13} \mathrm{C}$ NMR $(\delta$ ppm; $J \mathrm{~Hz})$ spectra were recorded on a Bruker Avance $300 \mathrm{MHz}$ NMR spectrometer using saturated $\mathrm{CDCl}_{3}$ solutions with $\mathrm{Me}_{4} \mathrm{Si}$ reference, unless indicated otherwise, with resolutions of $0.18 \mathrm{~Hz}$ and $0.01 \mathrm{ppm}$, respectively. Infrared spectra $\left(\mathrm{cm}^{-1}\right)$ were recorded as $\mathrm{KBr}$ discs using a Perkin Elmer System 2000 FT-IR spectrometer. UV-vis spectra were recorded using a Unicam UV 540 spectrometer. Melting point analyses were carried out using a Stewart Scientific SMP 1 melting point apparatus and are uncorrected. Electrospray (ESI) mass spectra were collected on an Agilent Technologies 6410 Time of Flight LC/MS. Compounds were dissolved in acetonitrile-water (1:1) solutions containing $0.1 \%$ formic acid, unless otherwise stated. The interpretation of mass spectra was made with the help of the program “Agilent Masshunter Workstation Software”. Magnetic susceptibility measurements were carried out at room temperature using a Johnson Matthey Magnetic Susceptibility Balance with $\left[\mathrm{HgCo}(\mathrm{SCN})_{4}\right]$ as reference. EPR spectra were recorded on a Bruker Elexsys E500 spectrometer, operated at the X-band and equipped with an Oxford Instruments cryostat. Fluorescence spectra, in emission mode, were recorded using a Jasco FP6300 fluorescence spectrophotometer. All measurements were made using $3000 \mu \mathrm{L}$ quartz 
cells. Microanalyses were carried out at the Microanalytical Laboratory of the National University of Ireland Maynooth. Standard Schlenk techniques were used throughout. Starting materials were commercially obtained and used without further purification. The compound 2-(2H-tetrazol-5-yl)pyridine (L1) has been reported previously. ${ }^{7 \mathrm{~b}}$

Caution! Nitrogen-rich compounds such as tetrazole derivatives are used as components for explosive mixtures. ${ }^{19}$ In our laboratory, the reactions described were run on a few gram scale, and no problems were encountered. However, great caution should be exercised when heating or handling compounds of this type.

\section{General procedure for ligand synthesis:}

To $\mathbf{L 1}$ (2.00 g, $13.6 \mathrm{mmol})$ dissolved in acetonitrile $(60 \mathrm{~mL})$ was added potassium carbonate $(3.76 \mathrm{~g}, 27.2 \mathrm{mmol})$. The resulting solution was heated to reflux for 30 minutes. To this hot solution was added ethyl bromoacetate $(2.27 \mathrm{~g}, 13.6 \mathrm{mmol})$. The reaction mixture was then stirred at reflux temperature for a further $24 \mathrm{~h}$. On cooling, inorganic salts were removed by filtration and the filtrate was concentrated under reduced pressure to afford an oil. This oil was purified by column chromatography on silica gel (pet. ether : ethyl acetate 1:2) to give the products $\mathbf{L} \mathbf{2 A}$ and $\mathbf{L} 2 \mathbf{B}$.

Ethyl 2-(5-(pyridin-2-yl)-1H-tetrazol-1-yl)acetate (L2A)

Orange solid (1.40 g, 44 \%). m.p. 53-55 ${ }^{\circ} \mathrm{C} . \mathrm{IR}(\mathrm{KBr}): \mathrm{v}=3015,2989,2970,1748,1591$, $1538,1474,1437,1378,1274,1251,1228,1117,1019,809,751,728 \mathrm{~cm}^{-1} .{ }^{1} \mathrm{H}$ NMR $\left(\mathrm{CDCl}_{3}\right): \delta=8.65(\mathrm{~m}, 1 \mathrm{H}, \mathrm{pyr}-\mathrm{H}), 8.43(\mathrm{~m}, 1 \mathrm{H}, \mathrm{pyr}-\mathrm{H}), 7.92(\mathrm{~m}, 1 \mathrm{H}, \mathrm{pyr}-\mathrm{H}), 7.44(\mathrm{~m}, 1 \mathrm{H}$, pyr-H), $5.74\left(\mathrm{~s}, 2 \mathrm{H}, \mathrm{CH}_{2} \mathrm{~N}\right), 4.19\left(\mathrm{q}, 2 \mathrm{H}, J=7.1 \mathrm{~Hz}, \mathrm{OCH}_{2}\right), 1.18\left(\mathrm{t}, 3 \mathrm{H}, J=7.1 \mathrm{~Hz}, \mathrm{CH}_{3}\right)$ ppm. ${ }^{13} \mathrm{C} \mathrm{NMR}\left(\mathrm{CDCl}_{3}\right): \delta=165.9(\mathrm{C}=\mathrm{O}), 152.1\left(\mathrm{CN}_{4}\right), 149.2,144.6,137.6,125.4,124.1$, 62.1, $51.1\left(\mathrm{CH}_{2} \mathrm{~N}\right), 14.0$ ppm. ESI-HRMS: calcd for $\mathrm{C}_{10} \mathrm{H}_{12} \mathrm{~N}_{5} \mathrm{O}_{2}[\mathrm{M}+1]^{+}$234.0986, found 234.0983 .

Ethyl 2-(5-(pyridin-2-yl)-2H-tetrazol-2-yl)acetate (L2B)

Yellow solid (1.08 g, 34 \%). m.p. 94-96 ${ }^{\circ} \mathrm{C}$. IR (KBr): v = 3001, 2958, 1745, 1596, 1520, 1467, 1417, 1368, 1345, 1231, 1051, 1032, 882, 797, $737 \mathrm{~cm}^{-1} .{ }^{1} \mathrm{H}$ NMR $\left(\mathrm{CDCl}_{3}\right): \delta=8.79$ (m, $1 \mathrm{H}$, pyr-H), 8.28 (m, $1 \mathrm{H}$, pyr-H), 7.88 (m, $1 \mathrm{H}$, pyr-H), 7.42 (m, $1 \mathrm{H}$, pyr-H), 5.50 (s, 2 
$\left.\mathrm{H}, \mathrm{CH}_{2} \mathrm{~N}\right), 4.28\left(\mathrm{q}, 2 \mathrm{H}, J=7.1 \mathrm{~Hz}, \mathrm{OCH}_{2}\right), 1.28\left(\mathrm{t}, 3 \mathrm{H}, J=7.1 \mathrm{~Hz}, \mathrm{CH}_{3}\right) \mathrm{ppm} .{ }^{13} \mathrm{C} \mathrm{NMR}$ $\left(\mathrm{CDCl}_{3}\right): \delta=164.7(\mathrm{C}=\mathrm{O}), 150.3\left(\mathrm{CN}_{4}\right), 146.5,143.1,137.1,125.0,122.5,62.7,53.5$

$\left(\mathrm{CH}_{2} \mathrm{~N}\right), 14.0$ ppm. ESI-HRMS: calcd for $\mathrm{C}_{10} \mathrm{H}_{12} \mathrm{~N}_{5} \mathrm{O}_{2}[\mathrm{M}+1]^{+}$234.0986, found 234.0979.

\section{$\left[\mathrm{Cu}(\mathbf{L} \mathbf{2 A}) \mathrm{Cl}_{2}\right]_{2}(\mathbf{1})$}

A solution of copper chloride dihydrate $(0.15 \mathrm{~g}, 0.86 \mathrm{mmol})$ in methanol $(20 \mathrm{~mL})$ was added to a solution of $\mathbf{L 2 A}(0.20 \mathrm{~g}, 0.86 \mathrm{mmol})$ in methanol $(20 \mathrm{~mL})$. The resulting solution was heated to reflux for two hours. The solution was then allowed to stand at room temperature for several days whereupon green crystals formed. Green crystals $(0.12 \mathrm{~g}, 39 \%)$. $\mathrm{C}_{20} \mathrm{H}_{22} \mathrm{Cl}_{4} \mathrm{Cu}_{2} \mathrm{~N}_{10} \mathrm{O}_{4}$ : calcd. C 32.65, H 3.02, N 19.05; found C 32.24, H 2.88, N 18.27. IR $(\mathrm{KBr}): \mathrm{v}=3101,2978,2947,1749,1616,1556,1481,1456,1373,1297,1261,1230,1111$, $1009,870,787,749 \mathrm{~cm}^{-1} . \lambda_{\max }(\mathrm{MeOH}) 872 \mathrm{~nm}, \varepsilon=89 \mathrm{M}^{-1} \mathrm{~cm}^{-1}$. Magnetic moment: 1.7 B.M.

\section{$\mathrm{Cu}(\mathbf{L} 2 \mathbf{B})_{2} \mathrm{Cl}_{2}(\mathbf{2})$}

A solution of copper chloride dihydrate $(0.15 \mathrm{~g}, 0.86 \mathrm{mmol})$ in methanol $(20 \mathrm{~mL})$ was added to a solution of $\mathbf{L 2 B}(0.20 \mathrm{~g}, 0.86 \mathrm{mmol})$ in methanol $(20 \mathrm{~mL})$. The resulting solution was heated to reflux for two hours. The solution was then allowed to stand at room temperature for several days whereupon blue crystals formed. Blue crystals $(0.15 \mathrm{~g}, 58 \%)$. $\mathrm{C}_{20} \mathrm{H}_{22} \mathrm{Cl}_{2} \mathrm{CuN}_{10} \mathrm{O}_{4}$ : calcd. C 39.96, H 3.69, N 23.31; found C 38.99, H 3.63, N 22.76. IR $(\mathrm{KBr}): \mathrm{v}=3005,2984,2967,1749,1611,1450,1388,1368,1283,1214,1018,875,799,756$ $\mathrm{cm}^{-1} . \lambda_{\max }(\mathrm{MeOH}) 800 \mathrm{~nm}, \varepsilon=61 \mathrm{M}^{-1} \mathrm{~cm}^{-1}$. Magnetic moment: 2.2 B.M.

\section{$\mathrm{Cu}(\mathbf{L 3 A}) \cdot \mathrm{H}_{2} \mathrm{O}(\mathbf{3})$}

Sodium hydroxide $(0.01 \mathrm{~g}, 0.43 \mathrm{mmol})$ in distilled water was added to a solution of $\mathbf{L 2 A}$ $(0.10 \mathrm{~g}, 0.43 \mathrm{mmol})$ in methanol $(10 \mathrm{~mL})$. The resulting solution was heated to reflux for 1 hour. After this time, copper chloride dihydrate $(0.07 \mathrm{~g}, 0.43 \mathrm{mmol})$ in methanol $(10 \mathrm{~mL})$ was added and an immediate blue precipitate resulted. The suspension was cooled to room temperature and the solid was removed by filtration. The blue solid obtained was dissolved in water and by slow evaporation, blue crystals of the product suitable for X-ray crystallography were obtained. $\mathrm{C}_{8} \mathrm{H}_{6} \mathrm{CuN}_{5} \mathrm{O}_{2} \bullet \mathrm{H}_{2} \mathrm{O}$ : calcd C 33.63, H 2.82, N 24.51; found C 33.22, H 2.64, N 
23.80. IR (KBr): $v=1651,1614,1587,1471,1456,1435,1392,1312,1250,1123,926,814$, $793,745,730 \mathrm{~cm}^{-1} . \lambda_{\max }(\mathrm{MeOH}) 656 \mathrm{~nm}, \varepsilon=23 \mathrm{M}^{-1} \mathrm{~cm}^{-1}$. Magnetic moment: 2.3 B.M.

$\mathrm{Cu}(\mathbf{L 3 A})_{2} \bullet \mathrm{H}_{2} \mathrm{O}(\mathbf{4})$

The ligand L2A (0.20 g, $0.86 \mathrm{mmol})$ was dissolved in a mixture of distilled water and methanol (10:1 ratio). Sodium hydroxide $(0.03 \mathrm{~g}, 0.86 \mathrm{mmol})$ in distilled water was added to this mixture and the solution was heated to reflux for 1 hour. Copper chloride dihydrate $(0.14$ $\mathrm{g}, 0.86 \mathrm{mmol}$ ) in water was added and the resulting solution was allowed to stand for several days whereupon blue block crystals formed. Blue crystals $(0.13 \mathrm{~g}, 65 \%)$. $\mathrm{C}_{16} \mathrm{H}_{14} \mathrm{CuN}_{10} \mathrm{O}_{5}$ (489.66): calcd. C 39.21, H 2.88, N 28.60; found C 40.09, H 2.55, N 28.95. IR (KBr): v = 3133, 3001, 2984, 1650, 1609, 1537, 1471, 1458, 1434, 1359, 1311, 1300, 1243, 1166, 1112, $808,790,752 \mathrm{~cm}^{-1} . \lambda_{\max }\left(\mathrm{H}_{2} \mathrm{O}\right) 748 \mathrm{~nm}, \varepsilon=10 \mathrm{M}^{-1} \mathrm{~cm}^{-1}$. Magnetic moment: 2.0 B.M.

$\mathrm{Cu}_{2}(\mathbf{L} 3 \mathbf{B})_{3}(\mathrm{OMe})(\mathbf{5})$

Sodium hydroxide $(0.01 \mathrm{~g}, 0.43 \mathrm{mmol})$ in distilled water was added to a solution of $\mathbf{L 2 B}$ (0.1 $\mathrm{g}, 0.43 \mathrm{mmol})$ in methanol $(10 \mathrm{~mL})$. The resulting solution was heated to reflux for 1 hour, in which time a white precipitate had formed. After this time, copper chloride dihydrate $(0.07 \mathrm{~g}$, $0.43 \mathrm{mmol}$ ) was added and an immediate blue precipitate resulted. The suspension was cooled to room temperature and the solid was removed by filtration. A pale green solid $(0.11$ g, $97 \%$ ) was obtained. $\mathrm{C}_{25} \mathrm{H}_{21} \mathrm{Cu}_{2} \mathrm{~N}_{15} \mathrm{O}_{7}$ : calcd C 32.41, H 2.40, N 22.23; found C 33.22, $\mathrm{H}$ 2.64, N 23.80. IR (KBr): v = 3095, 2959, 1659, 1635, 1608, 1571, 1448, 1367, 1286, 1215, $1158,1067,1028,912,823,799,759,730 \mathrm{~cm}^{-1} . \lambda_{\max }(\mathrm{DMSO}) 496 \mathrm{~nm}, \varepsilon=148 \mathrm{M}^{-1} \mathrm{~cm}^{-1}$. Magnetic moment: 2.5 B.M.

\section{$\mathrm{Cu}(\mathbf{L} \mathbf{3 B})_{2} \bullet 2 \mathrm{H}_{2} \mathrm{O}(\mathbf{6})$}

The ligand L2B (0.10 g, $0.43 \mathrm{mmol})$ was dissolved in a mixture of distilled water and methanol (10:1 ratio). Sodium hydroxide $(0.017 \mathrm{~g}, 0.43 \mathrm{mmol})$ in distilled water was added to this mixture and the solution was refluxed for 1 hour. Copper chloride dihydrate $(0.07 \mathrm{~g}, 0.43$ mmol) in distilled water was added and the resulting solution was cooled slowly. The resulting pale blue crystals were filtered and air dried. Pale blue crystals (0.09 g, $90 \%)$. 
$\mathrm{C}_{16} \mathrm{H}_{16} \mathrm{CuN}_{10} \mathrm{O}_{6}$ (507.67): calcd. C 37.82, H 3.18, N 27.58; found C 37.87, H 3.45, N 26.71. IR (KBr): $v=3195,3022,1728,1628,1614,1465,1453,1420,1376,1289$, 1221, 1174, $1164,1066,1031,826,797,731 \mathrm{~cm}^{-1} . \lambda_{\max }(760) \mathrm{nm}, \varepsilon=33 \mathrm{M}^{-1} \mathrm{~cm}^{-1}$. Magnetic moment: 1.80 B.M.

\section{$X$-ray structure determination}

Single-crystal X-ray data for all five structures 1-4 and 6 were collected on an Oxford Diffraction Gemini-S Ultra diffractometer at 294(1) K, with $\theta$ range 2-25 minimum and $100 \%$ data coverage to $25^{\circ}$ (on $\theta$ ). ${ }^{19}$ Data reduction procedures and absorption corrections are standard ${ }^{20}$ comprehensive details have been published elsewhere. ${ }^{21}$ All structures were solved using the SHELXS $97^{22}$ direct methods program and refined by full matrix least squares calculations on $F^{2}$ with all non-hydrogen atoms having anisotropic displacement parameters. Hydrogen atoms attached to carbon were treated as riding atoms using the SHELXS97 defaults at 294(1) K using the OSCAIL software whereas hydrogen atoms attached to water were allowed to refine with isotropic displacement parameters. ${ }^{23}$ Selected crystallographic and structural information are detailed in Table 1. Molecular diagrams (Figures 1 to 9) were generated using standard graphics packages. ${ }^{24}$ All searches and analyses of the Cambridge Structural Database (CSD) were performed with the November 2012 release (version $5.34+3$ updates). 13,25

The solutions and refinements proceeded without problems except for $\mathbf{3}$ which is a multicrystalline material which diffracted weakly.

CCDC reference codes 977671 to 977675 . Copies available, e-mail:deposit@ccdc.cam.ac.uk.

\section{Acknowledgements}

We are thankful to the Lundbeck Foundation for financial assistance (JMcG \& MJB), to NUIM and to the Irish Research Council for financial assistance through the provision of a John \& Pat Hume Fellowship and a Postgraduate Scholarship, respectively (US) and to Barbara Woods for carrying out the MS experiments. We are grateful to Dr. Høgni Weihe for 
EPR simulations and discussions. JFG thanks Dublin City University for grants in aid of research.

\section{References}

1. (a) N. Stock and S. Biswas, Chem. Rev., 2012, 112, 933-969; (b) J.-P. Zhang, Y.-B. Zhang, J.-B. Lin and X.-M. Chen, Chem. Rev., 2012, 112, 1001-1033; (c) R. Bertani, P. Sgarbossa, A. Venzo, F. Lelj, M. Amati, G. Resnati, T. Pilati, P. Metrangolo and G. Terraneo, Coord. Chem. Rev., 2010, 254, 677-695; (d) S. Qiu and G. Zhu, Coord. Chem. Rev., 2009, 253, 2891-2911; (e) R. J. Kuppler, D. J. Timmons, Q.-R. Fang, J.R. Li, T. A. Makal, M. D. Young, D. Yuan, D. Zhao, W. Zhuang and H.-C. Zhou, Coord. Chem. Rev., 2009, 253, 3042-3066; (f) R. Robson, Dalton Trans., 2008, $5113-$ 5131.

2. (a) K. Sumida, D. L. Rogow, J. A. Mason, T. M. McDonald, E. D. Bloch, Z. R. Herm, T.-H. Bae and J. R. Long, Chem. Rev., 2012, 112, 724-781; (b) R. B. Getman, Y.-S. Bae, C. E. Wilmer and R. Q. Snurr, Chem. Rev., 2012, 112, 703-724; (c) J.-R. Li, J. Sculley and H.-C. Zhou, Chem. Rev., 2012, 112, 869-932; (d) A. Bétard and R. A. Fischer, Chem. Rev., 2012, 112, 1055-1083; (e) L. E. Kreno, K. Leong, O. K. Farha, M. Allendorf, R. P. Van Duyne and J. T. Hupp, Chem. Rev., 2012, 112, 1105-1125; (f) Y. Cui, Y. Yue, G. Qian and B. Chen, Chem. Rev., 2012, 112, 1126-1162; (g) P. Horcajada, R. Gref, T. Baati, P. K. Allan, G. Maurin, P. Couvreur, G. Férey, R. E. Morris and C. Serre, Chem. Rev., 2012, 112, 1232-1268; (h) J.-R. Li, Y. Ma, M. C. McCarthy, J. Sculley, J. Yu, H.-K. Jeong, P. B. Balbuena and H.-C. Zhou, Coord. Chem. Rev., 2011, 255, 1791-1823; (i) Z.-Y. Gu, C.-X. Yang, N. Chang, X.-P. Yan, Acc. Chem. Res., 2012, 45, 734-745.

3. (a) R. Horikoshi and T. Mochida, Eur. J. Inorg. Chem., 2010, 5355-5371; (b) D. Banerjee and J. B. Parise, Cryst. Growth Des., 2011, 11, 4704-4720; (c) M.-L. Hua, A. Morsalib and L. Aboutorabi, Coord. Chem. Rev., 2011, 255, 2821-2859; (d) S. G. Baca, Int. Res. Jour. Pure Appl. Chem., 2012, 2, 1-24; (e) G. Aromi, L. A. Barrios, O. Roubeau and P. Gamez, Coord. Chem. Rev., 2011, 255, 485-546; (f) W.

Ouellette, S. Jones and J. Zubieta, Cryst.Eng.Comm., 2011, 13, 4457-4485; (g) L. Tian, Z. Niu, Z.-Y. Liu, S.-Y. Zhou and P. Cheng, CrystEngComm., 2013, 15, 10094 10099; (h) J.-Z. Liao, H. Ke, J.-J. Liu, Z.-Y. Li, M.-J. Lin, J.-D. Wang and C.-C. Huang, CrystEngComm., 2013, 15, 4830-4837. 
4. See, for example, (a) T. Wen, D.-X. Zhang and J. Zhang, Inorg. Chem., 2013, 52, 12-14; (b) S. Jones, A. Aldous, E. Burkholder and J. Zubieta, Polyhedron, 2013, 52, 582-590; (c) C.-C. Chang, Y.-C. Huang, S.-M. Huang, J.-Y. Wu, Y.-H. Liu and K.-L. Lu, Cryst. Growth Des., 2012, 12, 3825-3828; (d) B. K. Tripuramallu, P. Manna, S. N. Reddy and S. K. Das, Cryst. Growth Des., 2012, 12, 777-792; (e) M.-X. Li, H. Wang, S.-W. Liang, M. Shao, X. He, Z.-X. Wang and S.-R. Zhu, Cryst. Growth Des., 2009, 9, 4626-4633.

5. (a) G. H. Xu, T. Hang, K. J. Pan and Q. Ye, J. Coord. Chem., 2009, 62, 2457-2464;

(b) Q.-Y. Li, G.-W. Yang, X.-Y. Tang, Y.-S. Ma, F. Zhou, W. Liu, J. Chen and H. Zhou, Inorg. Chem. Commun., 2010, 13, 254-257.

6. (a) J. Gaire, J. McGinley, A. Fleming and F. Kelleher. Tetrahedron, 2012, 68, 59355941; (b) A. D. Bond, A. Fleming, J. Gaire, F. Kelleher, J. McGinley, V. McKee and U. Sheridan. Polyhedron, 2012, 33, 289-296; (c) U. Sheridan, J. McGinley, J. F. Gallagher, A. Fleming and F. Kelleher. Polyhedron, 2013, 55, 169-178.

7. (a) R. Prajapati, L. Mishra, K. Kimura and P. Raghavaiah, Polyhedron, 2009, 28, 600-608; (b) Y.-C. Chen, K.-B. Wang and Y. Wang, Polyhedron, 2010, 29, 669-674; (c) A. Lan, L. Chen, D. Yuan, Y. Huang, M. Hong and X. Wang, Polyhedron, 2011, 30, 47-52; (d) X.-J. Deng, W. Gu, L.-F. Zeng, L. Wang and X. Liu, Polyhedron, 2011, 30, 2038-2044; (e) R-Q. Fan, L.-Y. Wang, H. Chen, G.-P. Zhou, Y.-L. Yang, W. Hasi and W.-W. Cao, Polyhedron, 2012, 33, 90-96; (f) M.-L. Han, S.-H. Li, L.-F. Ma and L-Y. Wang, Inorg. Chem. Commun., 2012, 20, 340-345.

8. (a) R. N. Butler and A. F. M. Fleming, J. Heterocycl. Chem., 1997, 34, 691-693; (b) P. A. Bethel, M. S. Hill, M. F. Mahon and K. C. Molloy, J. Chem. Soc., Perkin Trans. 1, 1999, 3507-3514; (c) A. Fleming, F. Kelleher, M. F. Mahon, J. McGinley and V. Prajapati, Tetrahedron, 2005, 61, 7002-7011; (d) A. D. Bond, A. Fleming, F. Kelleher, J. McGinley and V. Prajapati, Tetrahedron, 2006, 62, 9577-9581; (e) A. D. Bond, A. Fleming, F. Kelleher, J. McGinley, V. Prajapati and S. Skovsgaard, Tetrahedron, 2007, 63, 6835-6842; (f) A. D. Bond, A. Fleming, J. Gaire, F. Kelleher, J. McGinley and V. McKee, Tetrahedron, 2009, 65, 7942-7947; (g) A. Fleming, J. Gaire, F. Kelleher, J. McGinley and V. McKee, Tetrahedron, 2011, 67, 3260-3266.

9. P. Lin, W. Clegg, R. W. Harrinton and R. A. Henderson, Dalton Trans., 2005, 23882394.

10. A. W. Addison, T. N. Rao, J. Reedijk, J. Van Rijn and G. C. Verschoor, J. Chem. Soc., Dalton Trans., 1984, 1349-1356. 
11. (a) S. Stagni, S. Colella, A. Palazzi, G. Valenti, S. Zacchini, F. Paolucci, M. Marcaccio, R. Q. Albuquerque and L. De Cola, Inorg. Chem., 2008, 47, 10509-10521; (b) Y. Huang, L.-Z. Chen, R.-G. Xiong and X.-Z. You, Inorg. Chim. Acta, 2010, 363, 2512-2519; (c) J. M. Seco, M. de Araújo Farias, N. M. Bachs, A. B. Caballero, A. Salinas-Castillo and A. Rodríguez-Diéguez, Inorg. Chim. Acta, 2010, 363, 3194 3199; (d) Q.-Y. Li, G.-W. Yang, X.-Y. Tang, Y.-S. Ma, F. Zhou, W. Liu, J. Chen and H. Zhou, Inorg. Chem. Commun., 2010, 13, 254-257.

12. (a) M. F. Mahon, J. McGinley, A. D. Rooney and J. M. D. Walsh, Inorg. Chim. Acta, 2009, 362, 2353-2360; (b) S. Mandal, F. Lloret and R. Mukherjee, Inorg. Chim. Acta, 2009, 362, 27-37; (c) D. H. Jeong, W. J. Park, J. H. Jeong, D. G. Churchill and H. Lee, Inorg. Chem. Commun., 2008, 11, 1170-1173.

13. F. H. Allen, Acta Crystallogr. Sect. B-Struct. Sci., 2002, B58, 380-388.

14. G.-W. Yang, Q.-Y. Li, Y. Zhou, P. Sha, Y.-S. Ma, R.-X. Yuan, Inorg. Chem. Commun., 2008, 11, 723-726.

15. March's Advanced Organic Chemistry: Reactions, Mechanisms, and Structure. M. B. Smith, J. March, Wiley-Blackwell, 6 ${ }^{\text {th }}$ Edition, 2007.

16. (a) W.-Q. Kan, J. Yang, Y.-Y. Liu and J.-F. Ma, Polyhedron, 2011, 30, 2106-2113;

(b) S.-Y. Liao, W. Gu, L.-Y. Yang, T.-H. Li, M. Zhang, L. Wang and X. Liu, Polyhedron, 2012, 36, 38-44.

17. (a) B. Shankar, P. Elumalai, R. Shanmugam, V. Singh, D. T. Masram and M. Sathiyendiran, Inorg. Chem., 2013, 52, 10217-10219; (b) M. El Sayed Moussa, F. Friess, W. Shen, M. Hissler, R. Reau and C. Lescop, Chem. Commun., 2013,49,6158-6160; (c) R. D. Adams and M. Chen, Organometallics, 2011, 30, 5867-5872; (d) Y.-J. Li, Z.-Y. Deng, X.-F. Xu, H.-B. Wu, Z.-X. Cao and Q.-M. Wang, Chem. Commun., 2011, 47, 9179-9181; (e) S. Y.-L. Leung, W. H. Lam, N. Zhu and V. W.-W. Yam, Organometallics, 2010, 29, 55585569; (f) T. Niksch, H. Goerls, M. Friedrich, R. Oilunkaniemi, R. Laitinen and W. Weigand, Eur. J. Inorg. Chem., 2010, 74-94.

18. (a) J. Glerup and H. Weihe, Inorg. Chem., 1997, 36, 2816-2819; (b) I. Krivokapic, C. Noble, S. Klitgaard, P. Tregenna-Piggott, H. Weihe and A.-L. Barra, Angew. Chem. Int. Ed., 2005, 44, 3613-3616; (c) S. Piligkos, I. Laursen, A. Morgenstjerne and H. Weihe, Mol. Phys., 2007, 105, 2025-2030.

19. R. N. Butler in Comprehensive Heterocyclic Chemistry II (Eds.: A. R. Katritzky, C. W. Rees, E. F. V. Scriven), Permagon, Oxford, 1996, 4, pp. 621. 
20. ABSFAC and CrysAlisPro CCD/RED, Version 1. 171.33.55, 2010, Oxford Diffraction, Abingdon, Oxfordshire, U.K.

21. P. Mocilac, K. Donnelly and J. F. Gallagher, Acta Cryst. Section B, 2012, B68, 189203.

22. G. M. Sheldrick, Acta Crystallogr. Sect. A, 2008, A64, 112-122.

23. P. McArdle, J. Appl. Cryst., 1995, 28, 65.

24. A. L. Spek, J. Appl, . Cryst., 2003, 36, 7-13.

25. I. J. Bruno, J. C. Cole, P. R. Edgington, M. Kessler, C. F. Macrae, P. McCabe, J. Pearson and R. Taylor, Acta Crystallogr. Sect. B-Struct. Sci., 2002, B58, 389-397. 


\section{Metal-organic frameworks based on pyridyl-tetrazole ligands containing ester or carboxylate pendant arms.}

Ursula Sheridan, John F. Gallagher, Morten J. Bjerrum, Adrienne Fleming, Fintan Kelleher and John McGinley.

The coordination of pyridyl-tetrazole derivatives containing ester substituents, at either the $\mathrm{N}-1$ or $\mathrm{N}-2$ position of the tetrazole ring, with copper(II) chloride results in the formation of either $1: 1$ or $1: 2$ copper to ligand complexes, depending on the ligand. However, when the ester functionality is changed to a carboxylate

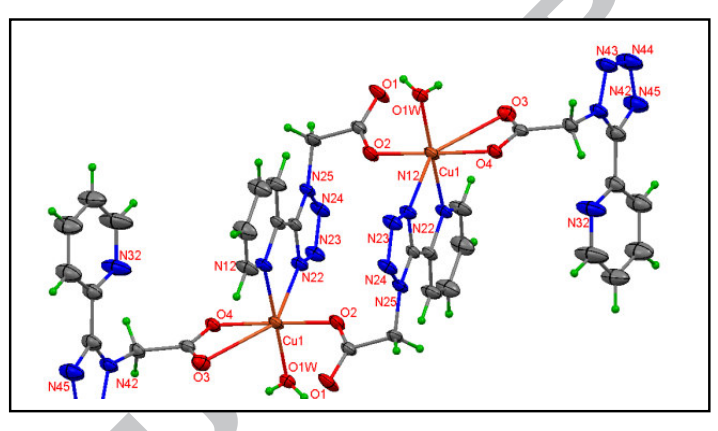
group, the resulting complexation reactions yield metal-organic frameworks, which vary dramatically depending on reaction conditions. For example, in complex 4 shown, each copper(II) ion is in a distorted octahedral geometry and a key feature of the molecular structure is that one of the $\mathbf{L 3 A}$ ligand (O1/O2/N12/N22) behaves in both a bridging (using O2/N12/N22) and chelating (via N12/N22) fashion while the second L3A ligand (O3/O4/N32/N42) is only involved in binding through its carboxylate group. 


\section{Highlights}

- First structural characterisation of copper complexes of pyridyl-tetrazole derivatives containing ester or carboxylate arms

- Formation of coordination polymers and metal-organic frameworks

- Complexes show increase in fluorescence compared to ligands alone 